\title{
Effects of Local Temperature Variation on Ventricular Fibrillation Dominant Frequency
}

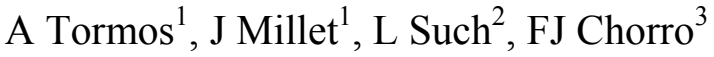 \\ ${ }^{1}$ Grupo BET, Universidad Politécnica de Valencia ${ }^{2}$ Departamento de Fisiología, Universidad de \\ Valencia ${ }^{3}$ Servicio de Cardiología, Hospital Clínico Universitario,Valencia, SPAIN
}

\begin{abstract}
By inducing controlled changes in the electrophysiologic properties of the whole heart, numerous studies have analysed the onset and maintenance mechanisms of ventricular arrhythmias. In this contribution a new method that cause local heterogeneities in the cardiac tissue is explained. A specific device, based on the Peltier effect, has been developed to quantify, in an experimental model (Langendorff-perfused), the temperature dependence of the dominant frequency (DF) during ventricular fibrillation (VF). This device performs changes of temperature above and below the basal value. With a drop of temperature, a valuable decrease of DF in the affected area, was observed. The differences between every step and control $\left(37^{\circ} \mathrm{C}\right)$ were significant, and the correlation of DF with temperature was high. At $42^{\circ} \mathrm{C}$ the fibrillation signals showed the main degree of organization, and the highest DF value.
\end{abstract}

\section{Introduction}

Techniques for epicardial recording of ventricular activation, employing multiple electrodes to register extracellular potentials, has provided valuable information about the characteristics of myocardial activation during ventricular arrhythmias. This information has given a methodological backup for some works on ventricular fibrillation, in which activation patterns and the existence of reentrant activity have been studied at the beginning of the arrhythmia as well as during its evolution [1]. In this line we can find in vitro studies whose experimental preparation consists of isolated Langendorff-perfused animal hearts [2]. Analysis of the fibrillation signal on frecuency domain is a widely used tool in the behavioral study over the time and space [3]. The dominant frequency (the one which presents the greater spectrum power) is often used for the characterization of the fibrillation signal [4].

On the other hand, similar studies analyze the way that controlled variations of temperature do affect to the electrophysiological properties of the heart and also to the activation process in normal conditions or during VF [5] . In those studies effects of global modifications are analyzed (working on the perfusion liquid), but it is also interesting to study what happens when neighbouring zones are affected by important temperature gradients. For example, the unequal sensibility of tissues under changes of temperature or the inhomogeneous modifications in the preparation can simulate pathological conditions that facilitate the apparition of arrhythmias, as well as it happens in situations of myocardial isquemia or in some structural alterations produced by straightening, fibrosis or cicatrization of myocardial zones. In short, the analysis of the influence of local variations of temperature can bring forward useful data about the mechanisms that explain the initiation or the sustenance of arrhythmias.

\section{Material and Methods}

Causing temperature variations in localized zones on the walls of the heart, while taking multipont recordings of the electric activity, presents a technical problem both for the methods and materials to use. In this research we have designed a system to make possible this kind of experimentation, capable therefore to register the unipolar electrograms of the epicardial mapping while cooling or heating the same surface in which the registration is being taken. After the system was developed and validated it was applied, in a first phase, to study the frecuencial content changes of VF signals with epicardial temperature.

\subsection{Multielectrode}

The main part of the temperature variation and registration device is an electrode matrix for the signal sense. For the construction of this multiple electrode "thick-film" microelectronic technology has been used. A Peltier Cell and other accessory elements complete the system mentioned.

The microelectronic circuits implemented with the thick-film hybrid technology are manufactured as deposition of successive layers of conductor, dielectric and resistive materials, by means of silkscreen processes, on a ceramic substrate that provides good thermal 
A

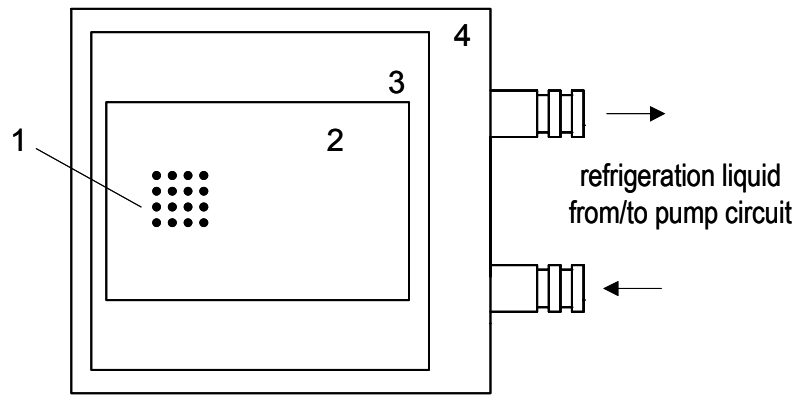

2

3

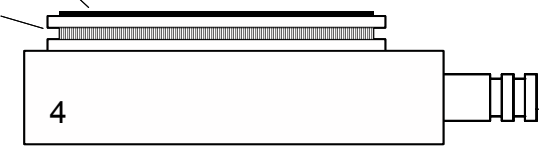

1 electrode array

2 substrate

3 Peltier cooler

4 aluminium block

Figure 1. Parts of the cooling/heating device. Top view (A) and side view (B).

conductivity.

The device acts like a thermal pump, continuously transfering heat of the cold face to the hot one, proportionally to the current injected. As far as the heat accumulated in the hot face can be extracted, the system is capable to reduce the temperature of the cold face efficiently, and so the material to which is thermally united. The exchange of the thermal behavior of both faces is possible by inverting the current direction.

The schematic drawing in the figure 1 shows the parts of the device developed as well as its distribution in a stratified disposition.

In the surface that will be in contact with the heart we have the following parts: multiple electrode in a ceramic substrate, Peltier Cell and aluminium refrigerator block. The matrix that conforms the multiple electrode makes contact on the epicardium just in a small zone. A thin adhesive sheet of low thermal resistance joins the substrate and transmits the heat to the cold face of the Peltier refrigerator. This one is connected to a power supply that drives the necessary current at each moment to obtain the temperatures desired in the epicardial surface. The heat is pumped by the Peltier effect toward the hot face of the thermoelectric refrigerator, where the aluminum heat exchanger block is in charge of keeping constant the temperature of this face, enabling the lowering of the temperature of the cold face. It has to be taken under consideration that the heart is continuously perfused with a nutritious liquid at $37^{\circ} \mathrm{C}$, which requires a continuous heat extraction flow. The disipation block consists of a watertight cavity, manufactured for this purpose, with a refrigerating liquid circulating through it, under the action of a centrifugal pump in a closed circuit. The system is completed whith two bipolar stimulation electrodes with lateral input, and an extraflat termocouple that is situated next to the matrix.

The electrode matrix consist of $4 \times 4$ electrodes of circular geometry, on an entire surface of $4.5 \times 4.5 \mathrm{~mm}$. The intercenter distance between electrodes is $1.5 \mathrm{~mm}$. Figure 2 shows schematic views of this multiple electrode before its assembly in the final device. For its implementation several layers have been serigraphied on a thin substrate of alumina $\left(\mathrm{Al}_{2} \mathrm{O}_{3}\right)$. A conductive silver paste is used for printing the tracks which conduct the electrical signal up to a few contacts of a weldable material of Palladium-Silver. A blue polymeric ink acts as a dielectric, covering the whole surface except for the points in contact with the cardiac tissue, which form the electrodes in strict sense. The process results in a multiple extraflat electrode which can be connected to the acquisition system by conventional welding in the corresponding terminations. The silver contacts have been chlorated by immersing the electrode in a constant current of ion chlorine solution, in order to stabilize his contact potential and to reduce the polarization impedance.

\subsection{Experimental preparation, protocol and data analysis}

The described electrodes have been used to record epicardial signals during VF in 15 experimental models (California rabbits). After anesthesia with ketamine and heparinization, the hearts were removed and immersed in cold $\left(4^{\circ} \mathrm{C}\right)$ Tyrode solution. After isolation, the aorta was connected to a Langendorff system for perfusion of Tyrode solution at a pressure of $60 \mathrm{mmHg}$ and a temperature of $37 \pm 0.5^{\circ} \mathrm{C}$. Oxygenation was carried out with a mixture of $95 \% \mathrm{O}_{2}$ and $5 \% \mathrm{CO}_{2}$. The designed multielectrode was situated at the epicardial surface of the lateral wall of left ventricle. The indifferent electrode was a $4 \times 6-\mathrm{mm}$ silver plaque located over the cannulated aorta. Recordings were obtained with a cardiac electrical activity mapping system (MAPTECH). The electrograms were amplified with a gain of 50-300, broadband (1-400 $\mathrm{Hz}$ ) filtered, multiplexed and recorded. The sampling rate for each channel was $1 \mathrm{kHz}$. The epicardial temperature was sensed (modified and control zone) with a miniaturized flat thermocouple, measured and registered
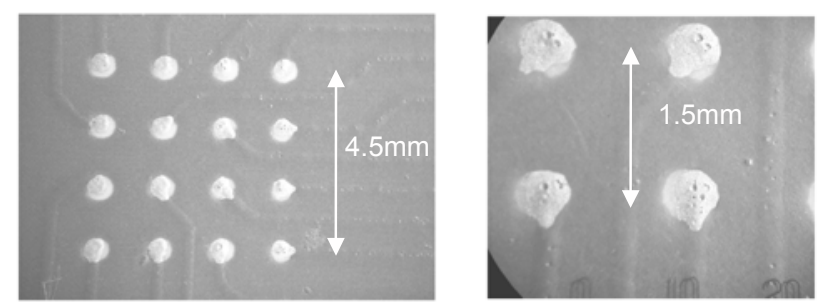

Figure 2. Views of the electrode at microscope. 
with a digital Fluke ${ }^{\circledR}$ thermometer.

VF was induced by pacing at increasing frequencies, maintaing coronary perfusion during the arrytmia. Two minutes after the onset of VF, the myocardial temperature was reduced in steps of $5^{\circ} \mathrm{C}$, from $37^{\circ} \mathrm{C}$ to $22^{\circ} \mathrm{C}$ and then increased in the same way up to $42^{\circ} \mathrm{C}$.

Welch's method was used to obtain the power spectrum of the signals recorded at the end of each temperature step (last 4 seconds of 5 minutes), for each electrode. The analysis was performed with data blocks of 4096 points (sampling rate $=1 \mathrm{kHz}$ ) and the dominant frequency was calculated as the average of the ones obtained for each electrode. Data processing was performed with software developed by our group for this purpose based on Matlab ${ }^{\circledR}[6]$. On the other hand, the activation times in each electrode were manually determined in MAPTECH software, so that the fibrillation interval (VV) histograms and mean values can be obtained, and then compared with DF for control. The measurement process in time domain has been performed using the epicardial mapping software MAPTECH. Statistical data are presented as mean values \pm standard deviation (SD).

\section{Results}

With a drop of temperature, a valuable DF decrease and VV increase in the affected area was observed in all cases. Graphical representation in Figure 3 shows the dependence, in absolute values, of DF and VV upon epicardial temperature. Table 1 contains numerical absolute and percentaged data of real temperature, DF and VV. Depending on the initial control $\left(37^{\circ} \mathrm{C}\right) \mathrm{DF}$ decayed, at $22^{\circ} \mathrm{C},-46.4 \pm 13.7 \%$. Moreover DF rised at $42^{\circ} \mathrm{C}$, up to $21.2 \pm 21.9 \%$, referenced now to the previous $37^{\circ} \mathrm{C}$ step, given that the highest value of temperature was rised increasing from the lowest value

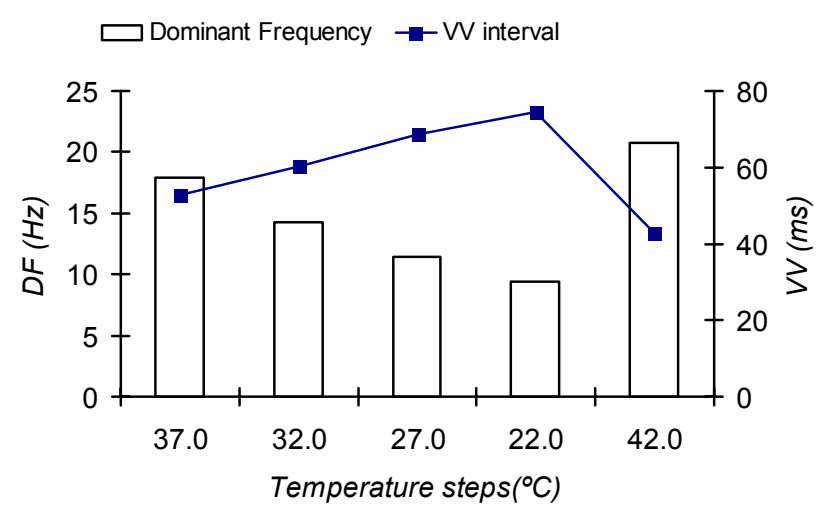

Figure 3. Dominant frequency (DF) and VV interval (VV) at temperature steps of $5^{\circ} \mathrm{C}$.

$\left(22^{\circ} \mathrm{C}\right)$. The differences between every step and control $\left(37^{\circ} \mathrm{C}\right)$ were significant $(p<0.001)$, greater in the first slope from $37^{\circ} \mathrm{C}$ to $32^{\circ} \mathrm{C}$ than in others. The correlation of $\mathrm{DF}$ and VV with temperature was high $(\mathrm{r}=0.97, \mathrm{p}<0.0001$ and $\mathrm{r}=-0.96, \mathrm{p}<0.0001)$. In all cases VF persisted.

An example of epicardial recordings during VF, at the established temperatures, are showed in figure 4 (left). The signals on the time domain clearly show a significant slowing with temperature decrease. At $42^{\circ} \mathrm{C}$ the fibrillatory signals have the highest DF value $(20.8 \pm 6.2$ $\mathrm{Hz}$ ) and their spectra more organized around the DF. In the same figure (right) the mean DF data, obtained at descendent steps, have been fitted to a linear model. The regresion straight line obtained on relating $\mathrm{DF}$ to temperature $(\mathrm{T})$ during cooling were significant in relation to the epicardial recordings of the left ventricle $(\mathrm{DF}=0.588 \cdot \mathrm{T}-4.056 ; \mathrm{r}=0.99 ; \mathrm{p}<0.05)$. In the experimental model used, DF did not differ from control values after suppressing cooling/heating.
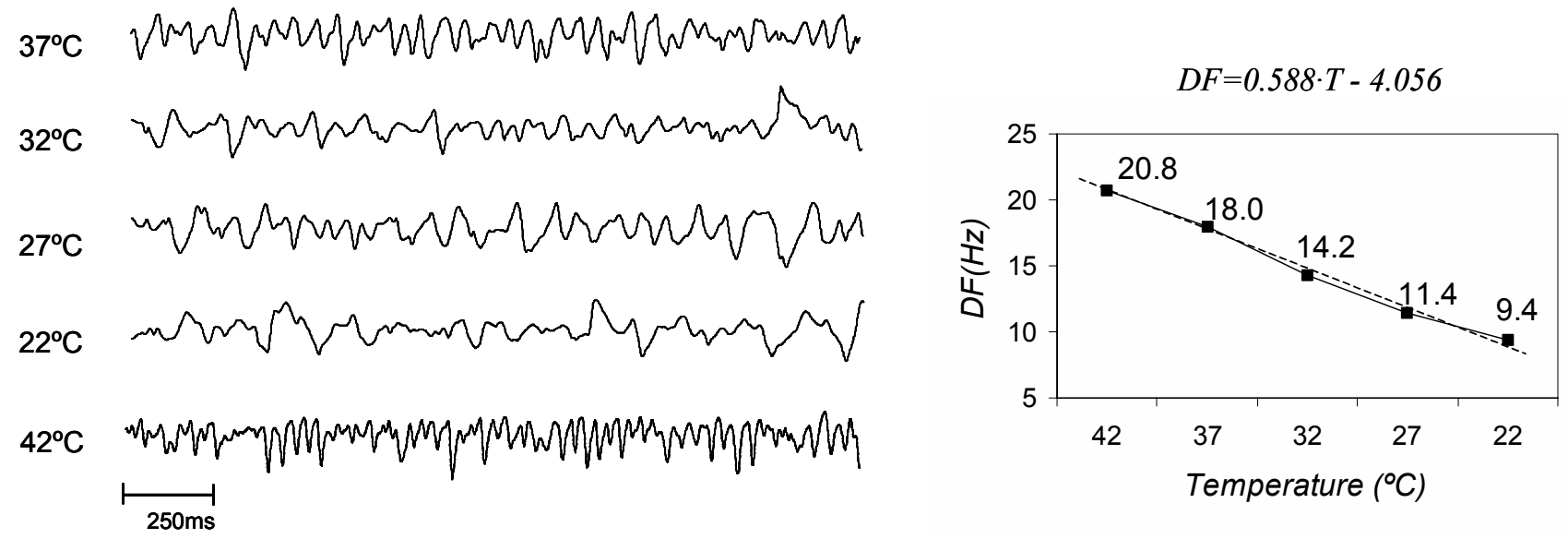

Figure 4. VF recordings obtained with 1 electrode situated in the modified area in one of the experiments (left). Data fit to the linear model of the DF with temperature drop (right). Numerical data correspond to mean of whole serie . 
Table 1. Temperature, dominant frequency (DF) and VV interval (VV) obtained at each temperature step (means \pm $\mathrm{SD})$, after 5 minutes. Data presented as absolute values and percentage of control.

\begin{tabular}{cccccc}
\hline Step $\left({ }^{\circ} \mathrm{C}\right)$ & Temperature $\left({ }^{\circ} \mathrm{C}\right)$ & DF $(\mathrm{Hz})$ & VV $(\mathrm{ms})$ & DF $(\%)$ & VV $(\%)$ \\
\hline 37 & $37.3 \pm 0.6$ & $18.0 \pm 4.3$ & $52.7 \pm 6.9$ & - & - \\
32 & $31.8 \pm 0.3$ & $14.2 \pm 4.5$ & $60.3 \pm 8.0$ & $-19.2 \pm 15.2$ & $12.5 \pm 11.5$ \\
27 & $26.9 \pm 0.6$ & $11.4 \pm 3.1$ & $68.7 \pm 10.6$ & $-33.7 \pm 19.7$ & $27.3 \pm 19.3$ \\
22 & $22.5 \pm 1.2$ & $9.4 \pm 2.5$ & $74.4 \pm 9.7$ & $-46.4 \pm 13.7$ & $34.6 \pm 19.8$ \\
42 & $42.0 \pm 0.1$ & $20.8 \pm 6.2$ & $42.6 \pm 6.7$ & $21.2 \pm 22.9$ & $-19.2 \pm 10.9$ \\
\hline
\end{tabular}

\section{Conclusion}

It has been presented a new method to modifying the temperature in a limited area of the epicardial surface and recording the electrogram at the same time, in isolated heart models. The developed device is capable of heating and cooling in a controlled mode, just the contact area from perfusion temperature.

With the application of this device to the quantification of dominant frequency on VF signal, it was found that the gradual cooling of a limited epicardial area, produces a slowing of VF. A linear correlation between VF activation frequency and epicardial temperature has been obtained. In the same way the epicardium heating has the contrary effect.

The arrythmia persists while local epicardial cooling (at least above $22^{\circ} \mathrm{C}$ ). The effects on dominant frequency subside after suppressing epicardial cooling/ heating.

\section{Acknowledgements}

This work was partly supported by FIS research grants PI020594 and CTIDIA/202/053.

\section{References}

[1] Jalife J. Ventricular fibrillation: Mechanisms of initiation and maintenance. Annu Rev Physiol 2000; 62:25-50.

[2] Allessie MA, Konings K, Kirchhof CJHJ, Wijffels M. Electrophysiologic mechanisms of perpetuation of atrial fibrillation. Am J Cardiol 1996; 77:10A-23A.
[3] Chorro FJ, Guerrero J, Cánoves J, Martínez-Sober M, Mainar L, Sanchis J, Calpe J, Llavador E, Espí J, LópezMerino V. Quantification of the modifications in the dominant frequency of ventricular fibrillation under conditions of ischemia and reperfusion. An experimental study. Pacing Clin Electrophysiol 1998;21:1716-1723.

[4] Gopalakrishnan M, Malkin RA. Two-dimensional analysis of ventricular fibrillation in the guinea pig. J Electrocardiol. 2003 Apr;36(2):147-53.

[5] Chorro FJ, Guerrero J, Ferrero A, Tormos A, Mainar L, Millet M, Cánoves M, Porres JC, Sanchis J, López-Merino $\mathrm{V}$, Such L. Effects of acute reduction of temperature on ventricular fibrillation activation patterns. Am J Physiol Heart Circ Physiol. 2002 Dec;283(6):H2331-40.

[6] Martínez A, Millet J, Chorro FJ, Cebrián A, Arredondo M T. Medmap: A Powerful Multichannel ELG Recordings Analizer. Annual International Conference of the IEEE Engineering in Medicine and Biology Society 2001.

Address for correspondence.

Alvaro Tormos.

Departamento de Ingeniería Electrónica.

Univ. Politécnica de Valencia.

Camino Vera 14 - 46022 SPAIN

atormos@eln.upv.es. 